\title{
Fluid homeostasis in chronic obstructive lung disease
}

\author{
P.W. de Leeuw*, A. Dees\#
}

Fluid homeostasis in chronic obstructive lung disease. P.W. de Leeuw, A. Dees. (C)ERS Journals Ltd 2003.

ABSTRACT: Chronic obstructive pulmonary disease (COPD) often leads to massive oedema and the development of what is usually called cor pulmonale. The mechanisms by which patients with COPD retain salt and water are not completely understood. Several abnormalities have been found including reduced renal blood flow with relatively preserved glomerular filtration rate and elevated levels of renin, aldosterone, arginine vasopressin and atrial natriuretic peptide. Generally, these abnormalities worsen with the severity of COPD and are most marked during the oedematous phases.

Cardiac output is remarkably normal, suggesting that "cor pulmonale" is not primarily a cardiac disorder but rather a condition of volume overload due to activation of sodium-retaining mechanisms. The stimulus for this activation could be underfilling of the arterial system (reduced effective circulating volume) secondary to a fall in total peripheral vascular resistance. The latter is caused by hypercapnia-induced dilation of the precapillary sphincters. Apparently, the massive sodium retention by the kidney is not able to restore the circulating volume and a vicious cycle ensues ultimately leading to a clinical picture which resembles right-sided heart failure. Predictably, only blockade of the effects of carbon dioxide at the level of the precapillary sphincters would be able to halt this process.

Eur Respir J 2003; 22: Suppl. 46, 33s-40s.

\author{
*Dept of Medicine, University Hospita \\ Maastricht, Maastricht and ${ }^{\#}$ Dept of Medi- \\ cine, Ikazia Ziekenhuis, Rotterdam, The \\ Netherlands. \\ Correspondence: P.W de Leeuw, Dept of \\ Medicine, University Hospital Maastricht, \\ P.O. Box 5800, 6202 AZ Maastricht, The \\ Netherlands. \\ Fax: 31433875006 \\ E-mail: p.deleeuw@intmed.unimaas.nl \\ Keywords: Chronic obstructive pulmonary \\ disease \\ cor pulmonale \\ natriuretic peptides \\ oedema \\ renal \\ renin-angiotensin system
}

Received and accepted June 302003
In the last century, applied physiology and functional pathology have become cornerstones in understanding mechanisms of disease and in developing rational forms of treatment. Indeed, the basic physiological principles that determine the homeostasis of the "milieu interieur" are also of relevance in disease states, either because they are defective or because they are activated to such an extent that they become detrimental. If the view of BERNARD [1] is accepted (and there is no reason not to accept it) that the ultimate goal of all physiological processes is to maintain as much as possible constancy of the internal environment, it is clear that the extracellular fluid, being the interface between the cells and the external milieu, must be the major target of all regulatory systems. A logical consequence of this reasoning is that, in the end, the kidney by virtue of its potential to adjust the size and composition of the extracellular fluid compartment, plays a paramount role in many, if not all, disease states.

In this Supplement of the European Respiratory Journal special attention is given to the systemic effects of chronic obstructive pulmonary disease (COPD). One of the manifestations of this illness is the development of (sometimes massive) oedema or, for that matter, disturbed volume control. The present paper aims to review some of the mechanisms that are involved in this complication. In that regard, the paper will first focus on the normal regulation of fluid homeostasis.

\section{Normal regulation of extracellular volume}

In a normal individual, $\sim 60 \%$ of the body consists of fluid. Two-thirds of the fluid volume is located intracellularly and one-third is extracellular water. About one-fifth to one-fourth of the extracellular fluid is contained within the vascular system (plasma water), while the remainder forms the interstitial fluid. Sodium, chloride and bicarbonate ions make up almost all of the total amount of solutes in the extracellular space [2]. Maintenance of the extracellular fluid compartment involves two different processes: control of its composition (concentration of solutes) and control of its size (volume). The respiratory system, for instance, regulates much of the carbon dioxide concentration in the extracellular fluid, while the kidneys amongst others determine the concentration of hydrogen. The total volume of the extracellular fluid is also regulated by the kidneys. It is important to realise that the latter is primarily accomplished not by adjusting water excretion but by modulating urinary sodium output. If the extracellular volume (ECV) is expanded, e.g. by saline infusion, the kidneys normally respond promptly by excreting the excess of sodium into the urine. This is followed by the excretion of water. Retention of sodium and water will occur with effective volume depletion.

As with other regulatory systems, volume control can be described in terms of an input function (afferent or sensory information), a central command unit and an output function (effector systems). The input signal for the volume control system mainly stems from arterial baroreceptors in the carotid sinus, aortic arch and juxtaglomerular apparatus. Rather than volume as such, these receptors respond to pressurerelated stretch at these sites of the circulation. Besides the arterial ones, there are also some sensors at the venous side (cardiopulmonary receptors) but their exact role remains somewhat elusive. The efferent limb of the volume control system comprises multiple humoral and neural mechanisms which ultimately affect the sodium excretory capacity of the kidney. The latter involves both alterations in renal 
haemodynamics and changes in tubular function. In case of volume loss, or other conditions leading to impaired arterial filling, reduced stretch of the carotid and aortic baroreceptors will activate the sympathetic nervous system while unloading of the renal receptors will lead to enhanced release of renin. These two systems, in concert with other effector mechanisms, will lower renal blood flow and enhance tubular reabsorption of sodium. Consequently, the kidney is stimulated to retain more sodium and water and to replenish the volume loss or to restore arterial filling. The opposite occurs when there is an excess of (arterial) volume.

In all likelihood, it is not the ECV as such that is being regulated and sensed by the afferent mechanisms but rather the "effective circulating volume" which is that part of the ECV that effectively perfuses the tissues or, in other words, fills up the arterial vasculature. The primacy for volume regulation, therefore, is the effective arterial blood volume [2]. Although changes in systemic blood pressure may sometimes be used to monitor changes in effective circulating volume, particularly in dehydrated persons, arterial pressure cannot be used as a substitute for circulating volume.

An important question that has not been completely solved yet is whether regulation of volume balance involves a predetermined set-point or a steady state regulation. Based on a number of arguments, HollenBerg [3,4] argued that the set-point of sodium balance for a normal person is that amount of sodium chloride in the body when the subject is in balance on a no-salt diet. According to this set-point theory, any increase in sodium intake above zero will suppress sodium-retaining mechanisms and induce a rapid disposal of the excess sodium. Conversely, no sodium will be excreted when the body is in a state of true volume depletion, i.e. below the set-point. This hypothesis of a fixed set-point has been disputed by others who claimed that at any level of sodium intake a new steady state level of body sodium is reached [5]. Whatever the mechanism, with an increase in dietary sodium, the ECV will expand until the moment that sodium output matches intake again. Thus, expansion of the ECV can occur under entirely normal circumstances. While these considerations may seem a bit trivial for the practising clinician, they are utterly important from a pathophysiological standpoint because knowing what exactly is regulated and how, is essential to understanding why oedema develops and why it is maintained.

\section{Fluid volume homeostasis in disease states: approach of the problem}

Although there are disorders which are characterised by a true deficit of the ECV, in many disease states overhydration, or an excess in ECV, due to enhanced retention of sodium and water is the problem. Among the latter are congestive heart failure, liver cirrhosis and nephrotic syndrome [2]. Clinically, the tendency to retain salt and water will usually be detected only after signs of fluid accumulation (e.g. oedema) have developed. Pathophysiologically, however, it is much more interesting to know what stimulus sets into motion the sequence of events that will eventually cause sodium retention. As for patients with COPD, this means that studies are preferentially carried out in the pre-oedematous stage and without treatment that could modify renal function. For obvious reasons, this is hardly possible.

Basically, there are three ways to assess whether fluid volume homeostasis in a particular group of patients is abnormal. Firstly, one can measure "static" volumes, e.g. extracellular volume, plasma volume (PV) or sodium space. In this regard, the term "static" is not meant to indicate that these volumes are motionless. On the contrary, the ECV is in a constant state of movement and is continuously being refreshed. It rather means that under steady state conditions the sizes of these volume compartments are relatively stable. A second approach could be to measure renal sodium excretory capacity. By administering an acute sodium load or by manipulating dietary intake to salt, one can examine whether the kidney responds appropriately by measuring sodium output over a given period of time. What is often overlooked, however, is that this requires prolonged monitoring. Indeed, a sluggish or exaggerated renal response in the early phases after a particular intervention may be followed by complete compensation thereafter. For instance, sodium excretory capacity may seem to be abnormal in the first $2 \mathrm{~h}$ after an acute saline load, yet be quantitatively normal on a 24-h basis. While this does not rule out disturbed volume control, the conclusions reached may be entirely different. Finally, one can measure several effector systems that play a role in the regulation of sodium excretion. From the combination of abnormalities one may then conclude whether abnormal sodium homeostasis is likely or not. It should be borne in mind, however, that many (patho)physiological responses related to volume control depend upon the prevailing level of sodium intake. Since increasing sodium intake expands the ECV [6], it is inappropriate to compare patients with widely varying degrees of salt consumption without paying due attention to this source of error.

\section{Body fluid volumes in chronic obstructive pulmonary disease}

Very few and conflicting data exist with respect to measurements of body fluid volumes in patients with COPD [7]. For instance, CAMPBELL et al. [8] found that exchangeable sodium was not only normal after treatment for oedema but also in two of three patients when gross oedema had developed again. This would mean that oedema formation is not, or at least not always, simply due to accumulation but rather to redistribution of fluid. On the other hand, there is data to show that the ECV is expanded in COPD [9-11]. One such example is the study of ANAND et al. [11]. These investigators followed nine patients with COPD who were admitted to hospital in respiratory failure with oedema after a respiratory infection. In all of them, ECV, PV, total body water and total exchangeable sodium were measured within 2 days and in some of them again after treatment. At the time of the measurements, patients had severe hypoxaemia and hypercapnia. From their data showing significant increases in all measured volumes which improved with treatment, the authors concluded that patients with oedema due to COPD had marked retention of sodium and water. They speculated that this was the result of the effect of hypercapnia on the kidney and neurohumoral systems. Close examination of their data, however, makes it clear that all their patients were in frank cardiac failure at admission. Moreover, sodium intake was not controlled and all medication, including diuretics, were continued. While it may not be possible to study patients under standardised conditions without confounding by medication or other factors, data such as those described here do not allow either to conclude whether expansion of the ECV in COPD is a primary event or secondary to cardiac dysfunction. Nevertheless, the data also show that even after adequate treatment body fluid volumes remained well above normal values suggesting that patients with COPD are in a constant state of overhydration. Although the investigators found cardiac output in their patients to be fairly normal, it should be noted that blood pressure and systemic vascular 
resistance were low. One could argue, therefore, that cardiac output was subnormal in relation to vascular resistance and, hence, that there was underfilling of the arterial system. The resulting lowering of the effective circulating volume could have been the stimulus for ongoing retention of salt and water.

Taking the scarcely available information together, it is not clear to what extent and at what stage body fluid volumes are abnormal in patients with COPD. In particular, there is a lack of data concerning changes in ECV over time. While there is certainly volume excess at advanced stages when gross oedema is present, it is not known whether or not expansion of the ECV already occurs at earlier stages.

\section{Renal sodium excretion in chronic obstructive pulmonary disease}

Theoretically, both hypoxaemia and hypercapnia could alter renal sodium excretion. In a series of studies, FARBER and coworkers [12-15] demonstrated that clinically stable hypercapnic patients with COPD often exhibit impaired excretion of sodium and water. In addition, correlations have been found between the degree of hypercapnia and the impairment in sodium excretion. However, some caution is needed in the interpretation of these data because studies on renal sodium excretion are not very convincing if sodium intake is not controlled or if diuretics have not been discontinued long enough. This is particularly relevant for the above-cited studies in which the investigators followed their patients during a fixed sodium intake of 90 mmoles per day. Changes in cumulative sodium balance from the first day of this "load" onwards were used to describe sodium excretory capacity of the individuals. On that basis they noted, amongst others, that there were some patients who continued to lose sodium and water whereas others had virtually no change in cumulative sodium balance [15]. Renin and aldosterone levels correlated inversely with total sodium loss, both in patients with severe but stable COPD [14] and in those with acute respiratory failure [15]. The authors concluded that excessive secretion of renin and aldosterone in hypercapnic patients leads to disturbed sodium excretion. In the current authors' view, however, this conclusion is not justified because there is no information about salt intake prior to the sodium "load". In other words, what the authors really studied was the immediate renal response to a dietary regimen in patients with, in all likelihood, varying amounts of sodium intake prior to study. It is conceivable, therefore, that the patients with lower renin and aldosterone levels had a higher sodium intake, i.e. above 90 mmoles per day prior to study, while the others may have been more sodium-restricted. This is supported by the fact that renin levels were comparable after 5 days, at a time that one can expect the groups to have reached a new state of sodium balance. Accordingly, differences in pre-test salt intake could equally well explain the differences in cumulative sodium balance. At any rate, this consideration underscores the point made by several others that meaningful statements about differences in sodium homeostasis between individuals require at least some observations when subjects are in balance on the same diet. This critique is also applicable, for instance, to the study by STEWART et al. [16] who infused a $2.7 \%$ saline infusion into 10 patients with stable cor pulmonale and 10 control patients with hypoxaemic chronic obstructive disease with no history of oedema. Although this study was set up to evaluate the role of atrial natriuretic peptide (ANP), it is worthwhile mentioning that the amount of sodium excreted was significantly lower in the cor pulmonale patients than in the controls. However, basal sodium output was also substantially lower and prior diuretic use higher in the cor pulmonale group. In other words, the control group probably operated at a higher sodium intake and a more expanded ECV than the cor pulmonale patients before the experiment. Under these circumstances it is not surprising at all that the excreted fraction of the sodium load was higher in the controls [3]. In a later study [17] the same group of investigators compared patients with COPD and either no significant decrease in arterial oxygen tension (group A), or hypoxaemia without oedema (group B) or severe hypoxaemia with oedema (group C). Urinary sodium excretion was followed for $4 \mathrm{~h}$ after an intravenous hypertonic saline load. The urinary excretion of sodium was significantly different between the groups and lowest in group $\mathrm{C}$ (about half of that in group A). Unfortunately, there is no information about pre-test sodium intake which may have contributed to the differences. In addition, no data were provided beyond the 4-h time window so that it is still possible that there was only a sluggish renal response to the sodium load and not necessarily an absolute impairment of sodium excretion in the oedematous patients. Similarly, in a study that was primarily designed to evaluate responses of ANP and brain natriuretic peptide to hypertonic saline infusion in patients with oedematous or non-oedematous COPD, SHEEDy et al. [18] found the former group to excrete significantly less of the load than the patients without a history of oedema. Again, no information was provided on pre-test sodium intake. Thus, it cannot be excluded that the patients without oedema excreted more sodium because they were in balance on a higher level of intake.

The separate influence of hypoxaemia on sodium output has been assessed in several studies. In one of these, REIHMAN et al. [19] evaluated the effect of reduced oxygen tension on two separate days in 11 clinically stable, non-oedematous hypercapneic patients who required long-term supplemental oxygen. On one of these days supplemental oxygen was removed (resulting in an average arterial oxygen tension $\left(\mathrm{Pa}, \mathrm{O}_{2}\right)$ of $\left.5.2 \mathrm{kPa}(39 \mathrm{mmHg})\right)$, while at the other occasion subjects were studied under their normal circumstances (average $\mathrm{Pa}_{2} \mathrm{O}_{2} \quad 10.6 \mathrm{kPa}(80 \mathrm{mmHg})$ ). The order of these investigations was randomised. Three days before the study diuretics were discontinued and patients were given a fixed amount of sodium $(90 \mathrm{mmol})$ per day. On both experimental days the renal response to a water load and a hypertonic $(3 \%)$ saline load was studied. The results of these experiments show that hypoxaemia causes a significant fall in (stimulated) urinary sodium output with no change in water excretion. Fractional reabsorption of sodium remained unchanged suggesting that tubular function was intact. Most likely, the reduction in sodium excretion was due to a decline in glomerular filtration rate.

In a reverse experiment using oxygen supplementation instead of withdrawal, MANNIX et al. [20] studied five patients with COPD and "mild" oedema who had been maintained on a $90 \mathrm{mmol} \cdot \mathrm{day}^{-1}$ sodium diet for 2 weeks. Sodium excretion was followed during 1 week of breathing room air and 1 week on supplemental oxygen. A significant difference in sodium output was found for the periods with and without supplemental oxygen $\left(67 \pm 7\right.$ and $102 \pm 10 \mathrm{mmol} \cdot 24 \mathrm{~h}^{-1}$ respectively). Since hypercapnia was similar during these 2 weeks, the authors concluded that correction of hypoxaemia results in enhanced natriuresis and that hypoxaemia, at least in the presence of hypercapnia, contributes to sodium retention in COPD. Because these observations were obtained while patients were continuing their fixed sodium diet, the results seem pertinent, even though the two time periods were not randomised. However, there are still some inconsistencies. Close examination of the data, given in a figure, reveals that 
sodium output during the first 4 days on room air was well below intake but rose gradually thereafter. The higher values after the introduction of oxygen may, therefore, have been fortuitous. It is also difficult to see how sodium balance could be positive in both periods (400 versus 610 mmols) with an increase in weight during the period of "enhanced" natriuresis. Therefore, the only logical explanation is that patients were already adhering to a low-salt diet when they first entered the study. A further problem in the interpretation of the data is the lack of creatinine determinations in the same urine collections that sodium was measured in. This means that there is absolute uncertainty about the completeness and reliability of the 24-h urine collections. Other studies that have looked into urinary sodium excretion in patients with COPD and normal controls [21, 22] can be criticised on similar grounds or because medication (diuretics) could not be eliminated for a sufficiently long period of time or because the observation period was too short. Nevertheless, studies in normal subjects who also respond to acute hypoxia with a reduction in sodium output $[22,23]$ support the notion that a fall in $\mathrm{Pa}, \mathrm{O}_{2}$ is associated with enhanced retention of sodium.

Unfortunately, the present authors cannot escape the conclusion that the available literature on sodium excretion in COPD falls short of standardisation. Habitual sodium intake and the use of diuretics are among the most conspicuous confounders. It is often impossible to stop diuretic treatment but even when it is discontinued, this was usually only done for a few days. Under these conditions one can expect a greater tendency of the organism to retain as much sodium as possible. Definite conclusions on the renal excretory capacity of sodium, therefore, cannot be drawn with certainty and have to await even more elaborate studies with rigorous control of sodium intake and, preferably, concomitant assessment of body fluid volumes. Nevertheless, it seems likely that patients with COPD express an impaired ability to excrete sodium (at least acutely) and that their kidneys are in a sodium-retaining state. This may be true already in the presence of hypoxaemia but becomes particularly evident when there is also hypercapnia.

\section{Effector systems in chronic obstructive pulmonary disease}

\section{Renal haemodynamics and tubular function}

Over the past fifty years several attempts have been made to characterise renal function in patients with COPD. The overall picture emerging from the literature is that of reduced renal blood flow with glomerular filtration rate being maintained for a long period of time [7, 24-29]. Renal blood flow is severely depressed in patients with acute exacerbations and/or extensive oedema but improves with adequate treatment [11]. Interestingly, cardiac output is usually (near-)normal, even in severe COPD, indicating that the renal fraction, i.e. that part of the cardiac output flowing through the kidneys, is reduced. This effectively rules out the possibility that changes in renal perfusion only passively follow alterations in cardiac performance but rather points towards preferential renal vasoconstriction. Although the mechanisms responsible for this vasoconstriction have not been fully elucidated, they are likely to involve the effects of abnormal gas tensions. Whether mild hypoxaemia has any influence on the kidney is difficult to tell. Several data suggest that it has no appreciable effect as long as hypoxaemia is very mild without concomitant hypercapnia [14, 15, 26]. More severe hypoxaemia, on the other hand, seems to be more consistently associated with reduced renal flow [28, 30-32].
Still, supplemental oxygen may already lower renovascular resistance and improve flow in normocapnic hypoxaemic patients. Since dopamine also increases renal blood flow [30], these data indicate that most of the rise in renal vascular resistance is not related to structural but rather to functional elements.

In the presence of hypercapnia renal perfusion progressively falls and inverse relationships between arterial carbon dioxide tensions and renal plasma flow such as the one depicted in figure 1 have been described repeatedly. When hypercapnia complicates COPD, the vasodilatory responses to dopamine [30], L-arginine [33], protein loading [34] and even oxygen [30] are lost. Whether this means that structural changes make the renal vasculature less responsive, is not known. Indeed, an alternative explanation could be that hypercapnia activates a vasoconstrictor mechanism that is powerful enough to withstand vasodilatory stimuli. Renal blood flow is particularly low in patients with oedema but it may improve to some extent after treatment [11]. Normalisation, however, is not a realistic option.

Despite the decrease in renal blood flow, glomerular filtration rate (GFR) remains intact in many patients and falls only at relatively late stages of the disease or during acute episodes of exacerbation [11]. Accordingly, the filtration fraction (quotient of GFR over renal plasma flow) steadily increases as COPD worsens. In terms of renal physiology, a rise in filtration fraction (FF) may favour the proximal reabsorption of sodium and water because peritubular hydrostatic pressure is lower and oncotic pressure higher when a greater fraction of the glomerular fluid is filtered. Accordingly, in several reviews the point is taken that reduced renal blood flow with maintained GFR and increased FF is associated with and may even be the cause of enhanced sodium retention in COPD. In the current authors' view, this concept is too simplistic. For instance, in patients with essential hypertension at a certain stage similar renal haemodynamic abnormalities can be found as in COPD patients $[35,36]$. Yet, in the hypertensives there is no evidence for volume expansion or, for that matter, a tendency to retain sodium. In fact, hypertensives with an increased FF even excrete an acute sodium load faster than normal [35]. Thus, the renal haemodynamic pattern is in itself not sufficient to explain the dysregulation of fluid volume balance in COPD.

Since sodium retention is so tightly coupled to the presence of hypercapnia, it is tempting to speculate that carbon dioxide

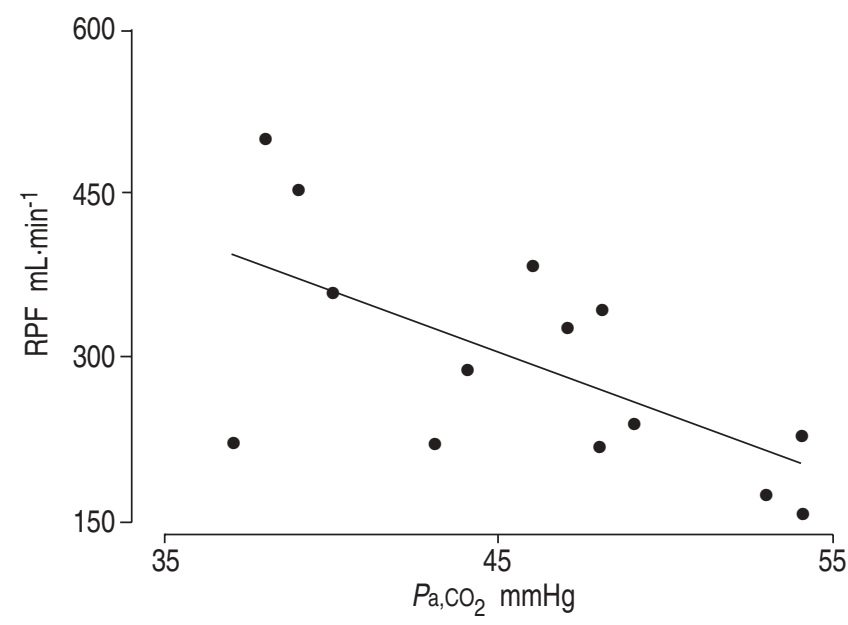

Fig. 1.-Relationship between renal plasma flow (RPF) and carbon dioxide arterial tension $\left(P_{\mathrm{a}}, \mathrm{CO}_{2}\right)$ in patients with chronic obstructive pulmonary disease, who were kept on supplemental oxygen. $r=-0.63$; $\mathrm{p}<0.05$. 
either directly, or via a humoral pathway, activates a sodiumretaining mechanism within the kidney. The most likely candidate in this respect would be the sodium-hydrogen $\left(\mathrm{Na}^{+/} \mathrm{H}^{+}\right)$-antiporter in the luminal membrane of proximal tubules which is involved in the buffering of respiratory acidosis at the expense of sodium gain in the body. So far, however, no clinical evidence has been delivered to support this notion.

\section{Neurohumoral factors}

Several neurohumoral systems are involved in sodium and water homeostasis. Except for the sympathetic system, these include the renin-angiotensin-aldosterone system, arginine vasopressin (AVP), ANP, endothelin, prostaglandins and dopamine to mention just a few. For the present discussion, the latter three are less relevant because there is relatively little data on these hormones in COPD.

Plasma catecholamines (noradrenaline, adrenaline) rise in response to progressive COPD and seem to be highest in oedematous patients with severe abnormalities [11]. Hypercapnia can directly stimulate the sympathetic system, thereby increasing the concentration of circulating catecholamines $[11,19,37]$. Although inverse correlations have been described between the degree of hypoxaemia and plasma levels of noradrenaline [37], oxygen treatment does not lower these levels, neither acutely [37] nor after prolonged administration [38]. The present authors' laboratory investigated 14 patients with COPD who were treated with long-term oxygen $\left(\mathrm{Pa}, \mathrm{O}_{2} \quad 8 \mathrm{kPa}(\geqslant 60 \mathrm{mmHg})\right)$. Although arterial levels of catecholamines correlated poorly with gas tension, mixed venous levels of adrenaline were inversely related to oxygen saturation and directly to the degree of hypercapnia (fig. 2). While this suggests that COPD patients are in a constant hyperadrenergic state, it is likely that this is more closely connected to central haemodynamics than to the kidney. Indeed, there is little, if any, direct evidence that the adrenergic system contributes to sodium retention in COPD. On the contrary, some data even suggest that the inability to excrete sodium is related to subclinical autonomic neuropathy [17].

Hypoxia and hypercapnia are also associated with

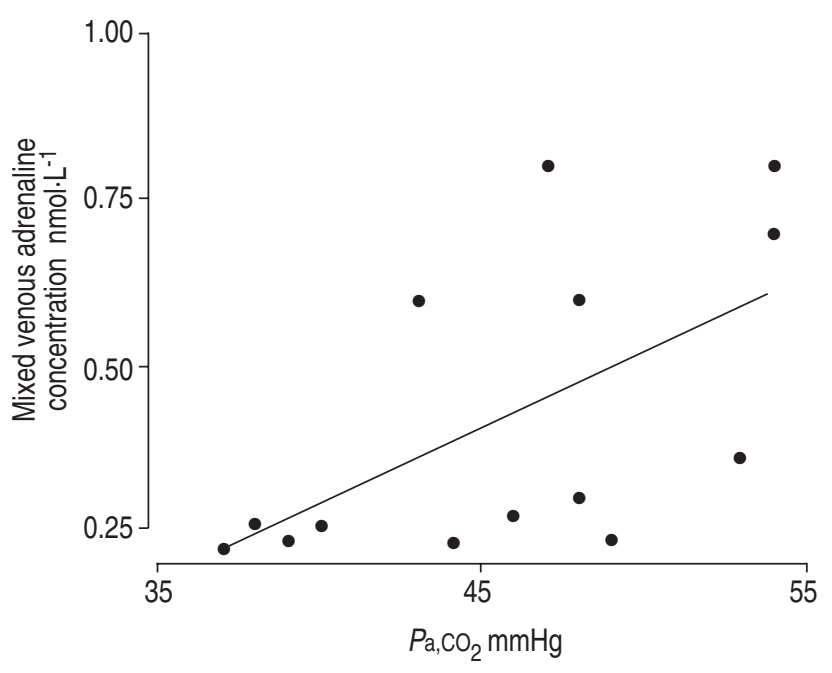

Fig. 2.-Relationship between mixed venous adrenaline levels and carbon dioxide arterial tension $\left(\mathrm{Pa}_{\mathrm{a}} \mathrm{CO}_{2}\right)$ in patients with chronic obstructive pulmonary disease, who were kept on supplemental oxygen. $\mathrm{r}=0.58 ; \mathrm{p}<0.01$. increased levels of renin [15, 23, 39-41]. This has often been attributed to the decline in renal perfusion but again this may be too simplistic an explanation because patients with essential hypertension often have low levels of renin in conjunction with impaired renal blood flow [36, 42]. Still, in COPD patients renin levels correlate inversely with the ability of the kidney to excrete sodium $[14,15]$. Several authors have described a dissociation between renin and aldosterone in the sense that aldosterone levels are relatively low for the degree of renin stimulation [27]. The cause for the relative suppression of aldosterone is not well known. Although aldosterone is higher in oedematous than in non-oedematous patients, it falls appropriately during saline loading in both groups [17]. Treatment with the angiotensin converting enzyme (ACE)inhibitor perindopril reduced basal levels of the hormone in the oedematous patients to levels seen in non-oedamatous subjects but did not affect the ability of the kidney to excrete a sodium load [43]. In another study, however, the ACEinhibitor captopril did induce a significant increase in sodium excretion, albeit without changes in renal plasma flow or plasma aldosterone [44]. These observations argue against aldosterone, and to some extent also against angiotensin II, as an important enhancer of sodium retention in COPD. Still, some caution is needed with this conclusion because the same caveats that were discussed in relation to studies on sodium excretion (vide supra) are applicable here.

AVP concentrations in COPD may be normal but are often elevated in more severe cases of COPD [11, 14, 15, 45]. Concentrations vary inversely with $\mathrm{Pa}, \mathrm{O}_{2}$, but there is little evidence that hypercapnia can directly stimulate AVP. By and large, responses of AVP to water loading appear to be normal in patients with COPD $[12,13]$. Concentrations of the peptide are clearly elevated in oedematous patients and inappropriately high in relation to the degree of hyponatraemia/hypoosmolality which is often present in severe cases of COPD [14]. This suggests that non-osmotic stimuli regulate the secretion of AVP under these circumstances. Increased AVP concentrations also correlate with an impaired ability to excrete a water load.

ANP also varies inversely with oxygen tension and seems to increase progressively with the severity of COPD [27, 40, 46]. The highest values are found in oedematous patients. Conversely, levels fall again with appropriate treatment. Infusion studies have shown that ANP responds normally to volume expansion and similarly in patients with or without oedema, even when renal sodium excretion is subnormal [16]. Apparently, the kidney is less sensitive to the changes in ANP.

Taking all data on the neurohumoral systems together, it is evident that both anti-natriuretic and natriuretic systems are activated in COPD. Probably, the balance between the two systems determines to what extent sodium will be excreted or retained. So far, however, it has not been possible to pinpoint one or more mechanisms that are primarily responsible for the avid retention of sodium and water in COPD.

\section{Why does oedema develop in chronic obstructive pulmonary disease?}

For oedema to develop there are two basic requirements: altered capillary dynamics and sodium retention by the kidney. The question is what comes first or in other words: is the tendency of the kidney to retain sodium appropriate or inappropriate? Early theories have suggested that oedema in COPD is secondary to right heart failure (cor pulmonale). This so-called "cardiac theory" presupposes that the right ventricle fails as a result of pulmonary hypertension $[7,28,29$, 47]. Sodium retention was thought to occur either in response 
to concurrent forward failure or because fluid was extravasated at the capillary level due to increased venous pressure (backward failure). Although these mechanisms may, indeed, be operative in some patients, in the majority no significant cardiac abnormalities can be found and cardiac output is usually normal even in oedematous patients [27]. One can even question, therefore, whether cor pulmonale really exists in COPD.

A second explanatory model for disturbed fluid homeostasis in COPD is the "renal theory". Since the development of oedema is almost invariably associated with hypercapnia, there must be a direct link between carbon dioxide retention and sodium retention. The common factor could be the $\mathrm{Na}^{+/} \mathrm{H}^{+}$-antiporter in the proximal tubules which acts to correct respiratory acidosis at the expense of volume expansion [29]. Many observations, including the effects of hypoxia and hypercapnia on volume-regulating hormonal systems and renin-mediated renal vasoconstriction would be consistent with this theory. There are, however, some fundamental problems with this paradigm. First of all, it assumes that in physiological terms the regulation of acidbase status takes higher priority than volume control. This would be totally illogical and against other observations that volume control has primacy over other regulatory systems. It would also be difficult to explain why, in the face of progressive disease with expansion of oedema, renin and AVP would still rise.

Like the cardiac theory, the renal theory explains the oedema by circulatory overflow which is not consistent with the hormonal data. In the present authors' view, therefore, the only theory that can adequately explain all findings is the "vascular theory". In this theory (fig. 3), it is underfilling which is the driving force behind the continuous expansion of the extracellular volume. Indeed, carbon dioxide is a potent vasodilator and an increase in this gas will substantially lower peripheral vascular resistance and increase arterial capacitance. Furthermore, due to the reduction in precapillary tone, the point of filtration equilibrium in the capillaries will move distally resulting in increased extravasation and loss of plasma volume. Consequently, the effective circulating

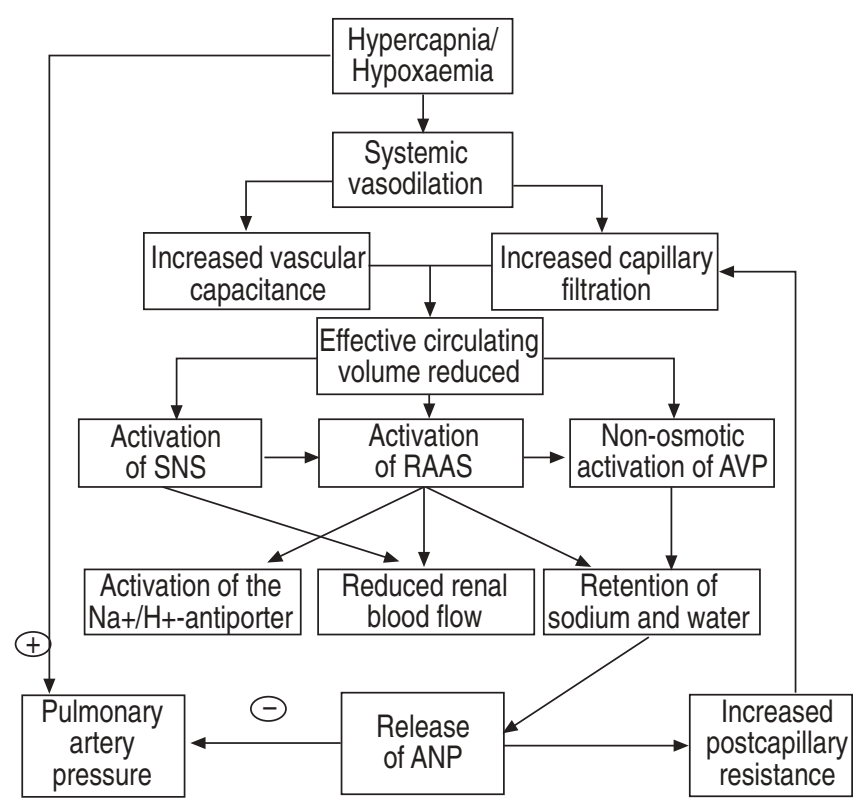

Fig. 3.-Hypothetical sequence of events to explain the development of oedema in chronic obstructive pulmonary disease. SNS: sympathetic nervous system; RAAS: renin-angiotensin-aldosterone system; AVP: arginine vasopressin; ANP: atrial natriuretic peptide. volume is reduced and this, in turn, will stimulate the sympathetic nervous system, renin and AVP. The kidney will respond (appropriately) with vasoconstriction and sodium retention to restore intravascular volume and tissue perfusion. Since not all of this volume can be kept within the vascular system, oedema develops. As long as hypercapnia is maintained and even more so when this worsens, there will be ongoing vasodilation, retention of sodium and water and aggravation of oedema. Of course, stimulation of the $\mathrm{Na}^{+/} \mathrm{H}^{+}$antiporter by the concurrent acidosis will contribute to further sodium gain. Non-osmotic release of AVP will eventually lead to hypo-osmolality. The normal cardiac output, seen in late stages of the disease, is still inappropriately low in relation to vascular filling and, thus, the stimulus for sodium retention remains. The use of diuretics will even aggravate this vicious cycle by further stimulating sodium loss and compensatory renin activation. Probably, ANP is stimulated as a consequence of the expanding ECV. In the current authors' view, in this cascade of events the raised ANP has both beneficial and detrimental effects. It is beneficial in the sense that it may help to relax the pulmonary vasculature and lower pulmonary artery pressure [48, 49]. At the same time, however, it constricts systemic postcapillary vessels [50], thereby further enhancing filtration and aggravating transcapillary fluid movements into the tissues. Experimental evidence supports this notion that ANP mediates the contraction of plasma volume during episodes of hypoxaemia [51]. Consequently, vascular filling will remain insufficient and sodium retention will continue. Finally, oedema worsens to a degree that it becomes intractable. Any attempt to mobilise the fluid by diuretics will be followed by still more retention of fluid until the heart really fails. Predictably, only blockade of carbon dioxide's effect at the level of the precapillary sphincters would halt this process. It would be worthwhile to examine the validity of this hypothesis.

\section{Future perspectives}

The regulation of the extracellular volume in patients with chronic obstructive pulmonary disease is still poorly understood. While the current authors favour the vascular theory to explain the problems with volume control in these patients, the authors realise that more research is needed to provide evidence for this hypothesis. In particular, more work should be done to evaluate haemodynamic and renal responses at various levels of sodium intake and with careful measurements of body fluid compartments. Unfortunately, available techniques are still not precise enough for such measurements. An interesting and potentially fruitful development would be the introduction of pharmacological agents which allow the vasodilatory response to carbon dioxide to be blocked. For the time being, however, it is more realistic to try to prevent deterioration of the disease and to rigorously treat acute exacerbations, preferably postponing the use of diuretics for as long as possible.

\section{References}

1. Bernard C. Lectures on the phenomena of life common to animals and plants. Springfield, Charles C Thomas, 1974.

2. Abraham WT, Schrier RW. Renal sodium excretion, edematous disorders, and diuretic use. In: Renal and Electrolyte Disorders. Schrier RW, ed. Philadelphia, Lippincott-Raven Publishers, 1997; pp. 72-129.

3. Hollenberg NK. Set point for sodium homeostasis: surfeit, deficit, and their implications. Kidney Int 1980; 17: 423-429. 
4. Hollenberg NK. Surfeit, deficit, and the set point for sodium homeostasis. Kidney Int 1982; 21: 883-884.

5. Bonventre JV, Leaf A. Sodium homeostasis: steady states without a set point. Kidney Int 1982; 21: 880-883.

6. Walser M. Phenomenological analysis of renal regulation of sodium and potassium balance. Kidney Int 1985; 27: 837841.

7. Richens JM, Howard P. Oedema in cor pulmonale. Clin Sci (Lond) 1982; 62: 255-259.

8. Campbell RH, Brand HL, Cox JR, Howard P. Body weight and body water in chronic cor pulmonale. Clin Sci Mol Med 1975; 49: 323-335.

9. Baum GL, Dick MM, Blum A, Kaupe A, Carballo J. Total body exchangeable potassium and sodium and extracellular fluid in chronic pulmonary insufficiency. Am Heart $J$ 1959; 4: 593-601.

10. Bauer FK, Telfer N, Herbst HH, Austin RC, Hetter B. Hyponatremia and increased exchangeable sodium in chronic obstructive lung disease. Am J Med Sci 1965; 250: 245-253.

11. Anand IS, Chandrashekhar Y, Ferrari R, et al. Pathogenesis of congestive state in chronic obstructive pulmonary disease. Studies of body water and sodium, renal function, hemodynamics, and plasma hormones during edema and after recovery. Circulation 1992; 86: 12-21.

12. Farber MO, Bright TP, Strawbridge RA, Robertson GL, Manfredi F. Impaired water handling in chronic obstructive lung disease. J Lab Clin Med 1975; 85: 41-49.

13. Farber MO, Kiblawi SS, Strawbridge RA, Robertson GL, Weinberger MH, Manfredi F. Studies on plasma vasopressin and the renin-angiotensin-aldosterone system in chronic obstructive lung disease. J Lab Clin Med 1977; 90: 373-380.

14. Farber MO, Roberts LR, Weinberger MH, Robertson GL, Fineberg NS, Manfredi F. Abnormalities of sodium and $\mathrm{H}_{2} \mathrm{O}$ handling in chronic obstructive lung disease. Arch Intern Med 1982; 142: 1326-1330.

15. Farber MO, Weinberger MH, Robertson GL, Fineberg NS, Manfredi F. Hormonal abnormalities affecting sodium and water balance in acute respiratory failure due to chronic obstructive lung disease. Chest 1984; 85: 49-54.

16. Stewart AG, Bardsley PA, Baudouin SV, et al. Changes in atrial natriuretic peptide concentrations during intravenous saline infusion in hypoxic cor pulmonale. Thorax 1991; 46: 829-834.

17. Stewart AG, Waterhouse JC, Billings CG, Baylis PH, Howard P. Hormonal, renal, and autonomic nerve factors involved in the excretion of sodium and water during dynamic salt and water loading in hypoxaemic chronic obstructive pulmonary disease. Thorax 1995; 50: 838-845.

18. Sheedy W, Stewart AG, Morice AH. Plasma levels of atrial natriuretic peptide and brain natriuretic peptide following intravenous saline infusion in oedematous chronic obstructive pulmonary disease and non-oedematous chronic obstructive pulmonary disease. Respiration 1996; 63: 376380.

19. Reihman DH, Farber MO, Weinberger MH, et al. Effect of hypoxemia on sodium and water excretion in chronic obstructive lung disease. Am J Med 1985; 78: 87-94.

20. Mannix ET, Dowdeswell I, Carlone S, Palange P, Aronoff GR, Farber MO. The effect of oxygen on sodium excretion in hypoxemic patients with chronic obstructive lung disease. Chest 1990; 97: 840-844.

21. De Angelis C, Perrone A, Ferri C, et al. Oxygen administration increases plasma digoxin-like substance and renal sodium excretion in chronic hypoxic patients. Am J Nephrol 1993; 13: 173-177.

22. De Siati L, Baldoncini R, Coassin S, et al. Renal sodium excretory function during acute oxygen administration. Respiration 1993; 60: 338-342.

23. Skwarski KM, Morrison D, Barratt A, Lee M, MacNee W. Effects of hypoxia on renal hormonal balance in normal subjects and in patients with COPD. Respir Med 1998; 92: 1331-1336.

24. Fishman AP, Maxwell $\mathrm{MH}$, Crowder $\mathrm{CH}$, Morales P. Kidney function in cor pulmonale. Particular consideration of changes in renal hemodynamics and sodium excretion during variations in the level of oxygenation. Circulation 1951; 3: 703-721.

25. Davies CE. Renal circulation in cor pulmonale. Lancet 1951; 2: $1052-1057$.

26. Kilburn KH, Dowell AR. Renal function in respiratory failure. Effects of hypoxia, hyperoxia, and hypercapnia. Arch Intern Med 1971; 127: 754-762.

27. MacNee W. Pathophysiology of cor pulmonale in chronic obstructive pulmonary disease. Part Two. Am J Respir Crit Care Med 1994; 150: 1158-1168.

28. Baudouin SV. Oedema and cor pulmonale revisited. Thorax 1997; 52: 401-402.

29. Palange P. Renal and hormonal abnormalities in chronic obstructive pulmonary disease (COPD). Thorax 1998; 53: 989-991.

30. Howes TQ, Deane CR, Levin GE, Baudouin SV, Moxham J. The effects of oxygen and dopamine on renal and aortic blood flow in chronic obstructive pulmonary disease with hypoxemia and hypercapnia. Am J Respir Crit Care Med 1995; 151: 378-383.

31. Baudouin SV, Bott J, Ward A, Deane C, Moxham J. Short term effect of oxygen on renal haemodynamics in patients with hypoxaemic chronic obstructive airways disease. Thorax 1992; 47: 550-554.

32. Sharkey RA, Mulloy EM, O'Neill SJ. The acute effects of oxygen and carbon dioxide on renal vascular resistance in patients with an acute exacerbation of COPD. Chest 1999; 115: $1588-1592$.

33. Howes TQ, Keilty SE, Maskrey VL, Deane CR, Baudouin SV, Moxham J. Effect of L-arginine on renal blood flow in normal subjects and patients with hypoxic chronic obstructive pulmonary disease. Thorax 1996; 51: 516-519.

34. Sharkey RA, Mulloy EM, Kilgallen IA, O'Neill SJ. Renal functional reserve in patients with severe chronic obstructive pulmonary disease. Thorax 1997; 52: 411-415.

35. Schalekamp MA, Krauss XH, Schalekamp-Kuyken MP, Kolsters G, Birkenhager WH. Studies on the mechanism of hypernatriuresis in essential hypertension in relation to measurements of plasma renin concentration, body fluid compartments and renal function. Clin Sci 1971; 41: 219231.

36. Schalekamp MA, Krauss XH, Kolsters G, Schalekamp MP, Birkenhager WH. Renin suppression in hypertension in relation to body fluid volumes, patterns of sodium excretion and renal haemodynamics. Clin Sci Mol Med 1973; 45: Suppl. 1, 283s-286.

37. Henriksen JH, Christensen NJ, Kok-Jensen A, Christiansen I. Increased plasma noradrenaline concentration in patients with chronic obstructive lung disease: relation to haemodynamics and blood gases. Scand J Clin Lab Invest 1980; 40: 419-427.

38. Bratel T, Wennlund A, Carlstrom K. Impact of hypoxaemia on neuroendocrine function and catecholamine secretion in chronic obstructive pulmonary disease (COPD). Effects of long-term oxygen treatment. Respir Med 2000; 94: 12211228.

39. Raff H, Levy SA. Renin-angiotensin II-aldosterone and ACTH-cortisol control during acute hypoxemia and exercise in patients with chronic obstructive pulmonary disease. $\mathrm{Am}$ Rev Respir Dis 1986; 133: 396-399.

40. Carlone S, Palange P, Mannix ET, et al. Atrial natriuretic peptide, renin and aldosterone in obstructive lung disease and heart failure. Am J Med Sci 1989; 298: 243-248.

41. Adnot S, Andrivet P, Chabrier PE, et al. Plasma levels of atrial natriuretic factor, renin activity, and aldosterone in 
patients with chronic obstructive pulmonary disease. Response to $\mathrm{O}_{2}$ removal and to hyperoxia. Am Rev Respir Dis 1990; 141: 1178-1184.

42. De Leeuw PW, Kho TL, Falke HE, Birkenhäger WH, Wester A. Haemodynamic and endocrinological profile of essential hypertension. Acta Med Scand 1978; 204; Suppl. $622,9-86$

43. Stewart AG, Waterhouse JC, Billings CG, Baylis P, Howard P. Effects of angiotensin converting enzyme inhibition on sodium excretion in patients with hypoxaemic chronic obstructive pulmonary disease. Thorax 1994; 49: 995-998.

44. Farber MO, Weinberger MH, Robertson GL, Fineberg NS. The effects of angiotensin-converting enzyme inhibition on sodium handling in patients with advanced chronic obstructive pulmonary disease. Am Rev Respir Dis 1987; 136: 862866.

45. Szatalowicz VL, Goldberg JP, Anderson RJ. Plasma antidiuretic hormone in acute respiratory failure. Am J Med 1982; 72: 583-587.

46. Winter RJ, Davidson AC, Treacher D, et al. Atrial natriuretic peptide concentrations in hypoxic secondary pulmonary hypertension: relation to haemodynamic and blood gas variables and response to supplemental oxygen. Thorax 1989; 44: 58-62.

47. MacNee W. Pathophysiology of cor pulmonale in chronic obstructive pulmonary disease. Part One. Am J Respir Crit Care Med 1994; 150: 833-852.

48. Adnot S, Andrivet P, Chabrier PE, et al. Atrial natriuretic factor in chronic obstructive lung disease with pulmonary hypertension. Physiological correlates and response to peptide infusion. J Clin Invest 1989; 83: 986-993.

49. Adnot S, Chabrier PE, Andrivet P, et al. Atrial natriuretic peptide concentrations and pulmonary hemodynamics in patients with pulmonary artery hypertension. Am Rev Respir Dis 1987; 136: 951-956.

50. Houben AJHM, Krekels MME, Schaper NC, Fuss-Lejeune MJMJ, Rodriguez S, Ade Leeuw PW. Microvascular effects of atrial natriuretic peptide (ANP) in man: studies during high and low salt diet. Cardiovasc Res 1998; 39: 442-450.

51. Albert TS, Tucker VL, Renkin EM. Atrial natriuretic peptide levels and plasma volume contraction in acute alveolar hypoxia. J Appl Physiol 1997; 82: 102-110. 